\title{
Religion and Female Genital Mutilation as Correlates of Maternal Mortality in Ekiti State
}

\author{
KONWEA, Patience Esohe ${ }^{1}$ FABAMISE, OLUFEMI MOSES ${ }^{2}$ \\ 1. Department of Human Kinetics and Health Education, Ekiti State University, Ado-Ekiti, Nigeria \\ 2. Department of Basic Medical Sciences, College of Health Sciences \& Technology, Ijero - Ekiti. Ekiti State, \\ Nigeria
}

\begin{abstract}
This study was to examine religion and female genital mutilation as correlates of maternal mortality in Ekiti State. The study adopted descriptive research design of the survey type which comprises of all 654 health personnel (Doctors and Nurses) in the seventeen (17) general and three (3) specialist hospitals in Ekiti State. The doctors (60 of them) were purposively and proportionately selected from the population while simple random sampling techniques was adopted in selecting 490 Nurses, making a total of 550 samples. A self-structured questionnaire titled: Religion and FGM as Correlates of Maternal Mortality (RFGMCMM) was used for data collection which were analysed using descriptive statistics (Charts) and inferential statistics of Pearson Product Moment Correlation (PPMC) was also used to test the hypotheses at 0.05 level of significance. The result showed that there was high maternal mortality cases in Ekiti state and it is as a result of erroneous religion believe and holding to old practice of female genital mutilation. Hence, it was therefore recommended that health workers and health professionals should map out an aggressive campaign and strategies to change the mind set of religious pregnant women by creating awareness on the need for regular antenatal care during pregnancy so that necessary anomalies would be corrected, hence reducing the menace of maternal death. Also, female genital mutilation should be totally condemned. Parents should be educated on the danger and consequences of this act hence averting possible complications during child delivery in the long run.
\end{abstract}

DOI: $10.7176 / \mathrm{JHMN} / 76-08$

Publication date:June 30th 2020

\section{Introduction}

The issue of maternal mortality in Nigeria has been adduced to both medical and social factors (religion and FGM) and it is believed that the way to take maternal mortality is to simultaneously deal with these factors. Female Genital Mutilation (FGM) is a custom or tradition synthesized over time from various values, especially religious and cultural values. The reasons for maintaining the practice include religion, custom, decreasing the sexual desire of women, hygiene, aesthetics, facility of sexual relations, fertility, etc. In general, it can be said that those who preserve the practice are largely women who live in traditional societies in rural areas. Most of these women follow tradition passively. It is common in several countries, predominantly in Africa, and more than 100 million women and girls are estimated to have had FGM worldwide. FGM is generally done in girls younger than 10 years and leads to varying amounts of scar formation. The presence of this scar tissue, which is less elastic than the perineal and vaginal tissue would normally be, might cause differing degrees of obstruction and tears or episiotomy (Shandall 2007). Studies have suggested that adverse obstetric outcomes such as episiotomy, tears, protracted labour, postpartum haemorrhage might be more common in deliveries in women who have had FGM (Hakim, 2012; De Silva, 2013).

Maternal mortality has been observed to be one of the major causes of death among women of reproductive age in Nigeria and remains a serious public health issue in developing countries. Maternal mortality refers to deaths due to complications from pregnancy or childbirth. It has also been described as the death of a woman while pregnant or within 42 days of termination of pregnancy, irrespective of the duration and site of the pregnancy, from any cause related to or aggravated by the pregnancy or its management but not from accidental or incidental causes (Shah \& Say 2007). According to WHO (2011) more than one women died every minutes from such cause, and 585,000 women die every year from the causes. Less than one percent of the deaths occur in developed countries demonstrating that they could be avoided in developing countries like Nigeria, if resources and services are available. Davies (2005) stated that maternal mortality is a measure of the risk to the mother connected with childbirth. Maternal deaths are only counted if they are directly related to pregnancy.

For every one that dies, 20-30 more suffer long term and short term disabilities such as chronic anemia, maternal exhaustion or physical weakness, vesico-vaginal or Rector-vaginal fistula, stress, incontinence, chronic pelvic pain, PID infertility, Ectopic pregnancy and Emotional Depression. The UNFPA estimates that 2 million women suffer vesico vaginal fistulae globally, $40 \%$ of these $(800,000)$ women are in Nigeria, majority due to prolonged obstructed labour that often terminate in still birth or neonatal death (UNFPA, 2008).

In a study by Etuk (2002), it was reported that most births in Nigeria do not take place in hospitals; therefore, the reported statistics do not accurately reflect the numbers of deaths during pregnancy and childbirth. Hospital 
statistics in Nigeria also suffer serious biases owing to selectivity and often lead to over or under estimate of the level of maternal mortality (Etuk, Etuk, Ekott \& Udoma 2000). Literature has also revealed Nigeria to be ranked as second globally as the country with the highest estimated number of maternal deaths with 37,000 cases of maternal deaths. For instance, in 2003 NDHS, it was estimated as 800/100 000 live births, whereas, in 2008 NDHS, the figure was 545/100 000 live births. Despite the reversal in the trend which shown an evidence of reduction, the rate is still considered to be high as indicated by WHO Maternal Mortality estimation guideline.

\section{Statement of Problem}

The high rate of Maternal Mortality in Nigeria is due to numerous causes which can be classified as either direct or indirect obstetric. The direct obstetric causes are related to complications of pregnancy, labor or in the 42-day post-partum period (puerperium), from incorrect treatment or interventions e.g. haemorrhage, sepsis, eclampsia, obstructed labor, unsafe abortion. The indirect obstetric causes are those resulting from a pre-existing disease or one that developed during pregnancy and that is aggravated by pregnancy e.g. anaemia, malaria, cardiovascular disease, hepatitis and diabetes (Ujah \& Ejej, 2005).

More so, some cultural practices also make child-bearing risky and expose women to the danger of death. Many Nigerian women live and work under cultural/religious conditions that do not allow them to reach their full potential. They are not allowed to take decisions for their health needs or in their reproductive lives, nor do they enjoy good health care (Federal Ministry of Health, FMoH, 2015). Religion may influence the use of modern health services, primarily the Mother and Child Health services, by paying attention to religious teachings, beliefs, practices, and church regulations that reinforce non-use of modern health services. The beliefs that some diseases and sicknesses have spiritual and religious undertones may prevent pregnant women from assessing health facilities.

Some Christians believed that the labour pain can be viewed as part of God's plan for mankind having disobeyed God's instructions after creation; hence, they refuse pain relief medications during pregnancy. Adeusi, Adekeye, \& Ebere (2014) describe that lack of interest or believe in drugs and medications could hinder effective service and care delivery, and this are what non-Christians would refer to as a mere 'coincidence' or 'karma', they would attribute this as the way God wants it to be. It is observed that what people believed in what they base their thoughts and emotions on and this in turn affects the biological system and social life.

It is also observed that Female genital mutilation could lead to prolonged and obstructed labour as a result of adhesions hence significantly likely to be a complicated caesarean section, postpartum haemorrhage, episiotomy which are clinical predisposing factors to maternal mortality. Female genital mutilation (FGM) consists of all procedures that involve partial or total removal of the external female genitalia or other injury to the female genital organs whether for cultural or other non-therapeutic reasons (WHO, 2007). However, while numerous studies have focused on the medical factors that causes maternal mortality, few had worked on socio-cultural factors such as religion and female genital mutilation as correlate of maternal mortality in Ekiti State.

\section{Purpose of the Study}

The purpose of this study was to examine religion and female genital mutilation as correlate of maternal mortality in Ekiti State. This study specifically examined whether maternal mortality is related to the religion of pregnant women and whether female genital mutilation is related to maternal mortality in Ekiti State.

\section{Research Questions}

The following research questions were raised for the study:

1. to what extent does religion of pregnant women contribute to maternal mortality in Ekiti State?

2. to what extent does female genital mutilation contribute to maternal mortality in Ekiti State?

\section{Research Hypotheses}

The following hypotheses were tested.

1. Religion of pregnant women is not a correlate of maternal mortality in Ekiti State.

2. Female Genital Mutilation is not a correlate of maternal mortality in Ekiti State.

\section{Significance of the Study}

The study would be of great benefit to mothers, health workers, hospital administrators, Government and NonGovernmental Organisations (NGO). Findings from this study could provide information on how religion and female genital mutilation could contribute to maternal mortality. Understanding and identification of these sociocultural factors that affect maternal mortality will be of importance to health educators because it will help in designing health education and health promotion programmes to provide right information on maternal mortality during antenatal and postnatal care. It is believed that the outcome of this study will benefit primary health workers to disseminate the right information on maternal health hence reducing mortality. 
Finally, this study will also be useful to all stakeholders in health sectors, especially non-governmental organizations(NGOs) and policy makers when planning and monitoring health programmes related to maternal health.

\section{Methodology}

The descriptive research design of the survey type was adopted for the study. It comprises of all 654 health personnel (Doctors and Nurses) in the seventeen (17) general and three (3) specialist hospitals in Ekiti State. The doctors (60 of them) were purposively and proportionately selected from the population while simple random sampling techniques was adopted in selecting 490 Nurses, making a total of 550 samples. A self-structured questionnaire titled: Religion and FGM as Correlates of Maternal Mortality (RFGMCMM) was used for data collection which were analysed using descriptive statistics (Charts) and inferential statistics of Pearson Product Moment Correlation (PPMC) was also used to test the hypotheses at 0.05 level of significance.

\section{Results and Discussion}

Descriptive Analyses

Question 1: To what extent does religion of pregnant women contributes to maternal mortality in Ekiti State?

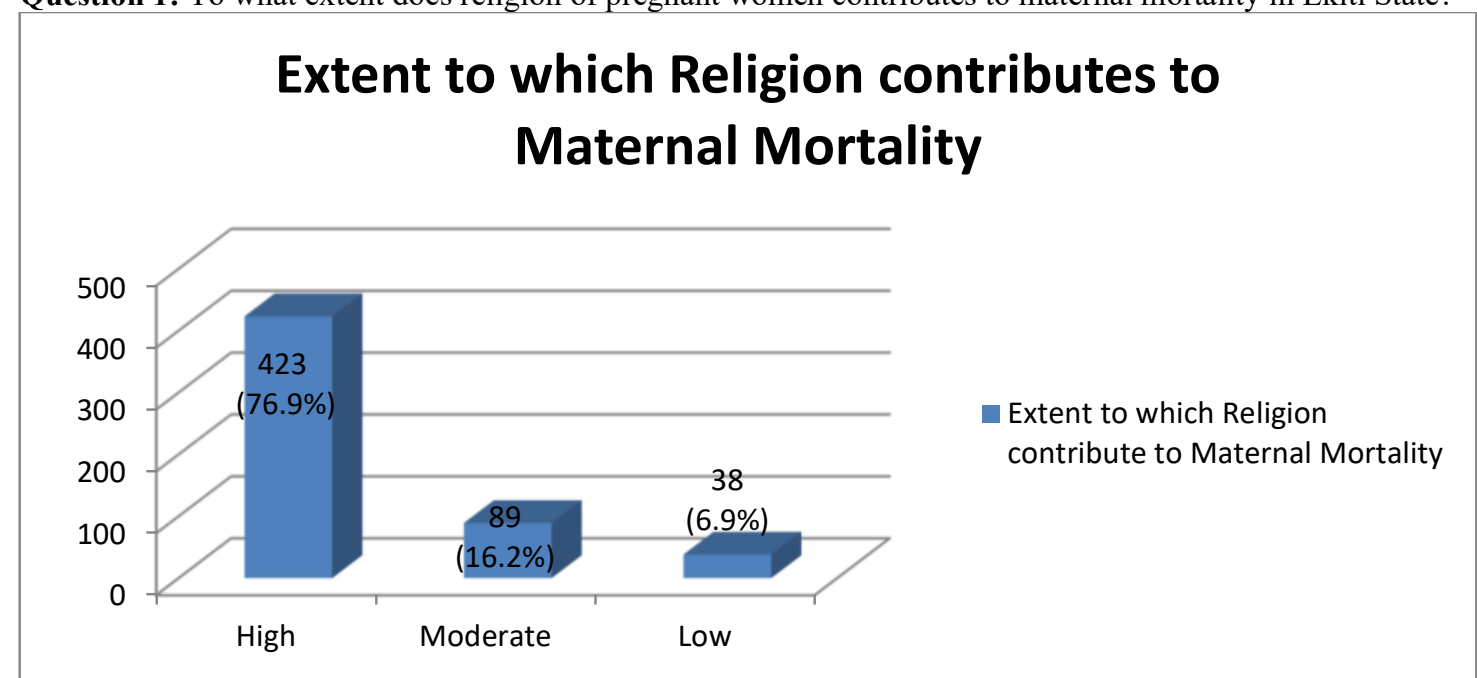

Figure 1: Bar Chart showing the extent to which religion of pregnant women contributes to maternal mortality in Ekiti State

Figure 1 revealed the extent to which religion of pregnant women contributes to maternal mortality in Ekiti State. It was revealed that out of 550 respondents sampled for the study, 423 representing $76.9 \%$ indicated that religion of pregnant women contributed to high extent on maternal mortality in Ekiti State.

Question 2: To what extent does female genital mutilation contribute to maternal mortality in Ekiti State?

\section{Extent to which Religion contributes to Maternal Mortality}

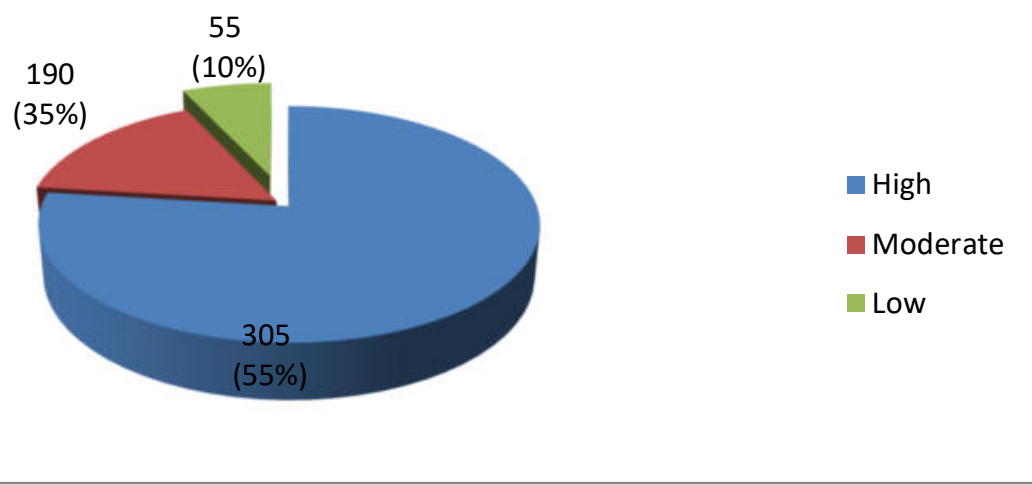

Figure 2: Pie Chart showing the extent to which female genital mutilation contributes to Maternal Mortality 
The pie chart in figure 2 revealed the extent to which female genital mutilation contributes to Maternal Mortality. It was revealed that out of 550 respondents, $305(55 \%)$ indicated that female genital mutilation contributed to a high extent on maternal mortality in the Ekiti state.

\section{Test of Hypotheses}

Hypothesis 1: There is no significant correlation between religion of pregnant women and maternal mortality in Ekiti State.

To test the hypothesis, responses relating to religion and maternal mortality in Ekiti state were computed using PPMC at 0.05 level of significance. The result is shown in table 1.

Table 1: Relationship between religion and maternal mortality in Ekiti State

\begin{tabular}{|l|l|l|l|l|l|l|}
\hline Variable & N & Mean & SD & r-cal & r-tab & Sig (P) \\
\hline Religion & 550 & 2.68 & 0.69 & & & \\
\cline { 1 - 3 } Maternal Mortality & 550 & 2.76 & 0.74 & $0.52^{*}$ & 0.23 & 0.02 \\
\hline
\end{tabular}

$\mathbf{P}<\mathbf{0 . 0 5} \quad$ *Significant

The result of analysis presented in table 1 revealed that there was high relationship between religion and maternal mortality in Ekiti state as $r_{\text {cal }}(0.52)$ was greater than $r_{\text {tab }}(0.23)$ and P-value (0.02) less than 0.05 level of significance. This led to the rejection of hypothesis one. Hence, religion is a significant correlate of maternal mortality in Ekiti state.

Hypothesis 2: There is no significant correlation between female genital mutilation and maternal mortality in Ekiti State

In order to test the hypothesis, responses relating to female genital mutilation and maternal mortality in Ekiti State were computed using PPMC at 0.05 level of significance. The result is shown in table 2.

Table 2: Relationship between female genital mutilation and maternal mortality in Ekiti State

\begin{tabular}{|l|l|l|l|l|l|l|}
\hline Variable & N & Mean & SD & r-cal & r-tab & Sig (P) \\
\hline Genital Mutilation & 550 & 2.85 & 0.81 & \multirow{2}{*}{$0.46^{*}$} & 0.23 & \multirow{2}{*}{0.02} \\
\cline { 1 - 4 } & 550 & 2.76 & 0.74 & & & \\
\hline
\end{tabular}

$\mathbf{P}<\mathbf{0 . 0 5} \quad *$ Significant

The result of analysis presented in table 2 revealed that there was high relationship between genital mutilation and maternal mortality in Ekiti state as $r_{\text {cal }}(0.55)$ was greater than $r_{\text {tab }}(0.23)$ and P-value (0.02) less than 0.05 level of significance. This led to the rejection of hypothesis two. Hence, female genital mutilation is a significant correlate of maternal mortality in Ekiti state.

\section{Discussion}

The finding of the study in research question one which sought to determine the extent to which religion of pregnant women contributes to maternal mortality in Ekiti State revealed that $76.9 \%$ of the respondent indicated that religion of pregnant women contributed to high extent on maternal mortality in Ekiti State. The null hypothesis was rejected which implies that there was high relationship between religion and maternal mortality in Ekiti state. This finding is in line with Birth (2010), that "what we believe is what we base our thoughts and emotions on". Some Christians believed that the labour pain is an act of God; hence, they refuse pain relief medications during pregnancy. Adeusi, Adekeye, \& Ebere (2014) describe that lack of interest or believe in drugs and medications could hinder effective service and care delivery, hence increasing the rate of maternal mortality among women during deliveries.

The finding of the study in research question two which sought to determine the extent to which female genital mutilation contributes to Maternal Mortality in Ekiti State revealed that female genital mutilation contributed to a high extent on maternal mortality in the Ekiti state. The null hypothesis two was rejected which means that there was high relationship between genital mutilation and maternal mortality in Ekiti state. This finding corroborate with Hakim (2012) and De Silva (2013) that adverse obstetric outcomes such as episiotomy, tears, protracted labour, postpartum haemorrhage are more common in deliveries in women who have had FGM. This becomes risky as most children born by women with FGM would have undergone undue stress, leading to maternal mortality.

\section{Conclusion}

Based on the findings of the study, it was concluded that there is high maternal mortality cases in Ekiti state and it is as a result of erroneous religion believe and holding to old practice of female genital mutilation. This ordeal however is common in Ekiti State as a result there is high occurrence of maternal mortality in the state.

\section{Recommendations}

The study recommends the following; 
1. Health workers and health professionals should map out an aggressive campaign and strategies to change the mind set of religious pregnant women by creating awareness on the need for regular antenatal care during pregnancy so that necessary anomalies would be corrected, hence reducing the menace of maternal death.

2. Female genital mutilation should be totally condemned. Parents should be informed by health workers on avoidance of this act and the negative implication during child delivery in the long run.

\section{References}

Adeusi, S. O, Adekeye, O. A. \& Ebere, L. O. (2014) . Predictors of maternal health as perceived by pregnant women in Eti-Osa, Lagos State, Nigeria. Journal of Education and Practice 5(18), 125-131.

Birth, E.P. (2010) "Medical care during pregnancy". The Nemours foundation.Fromhttp://kidshealth.org/parent/pregnancy_newborn/index.html Retrieved August, 2008.

Davies, E.M. (2005). Short inter-pregnancy intervals, parity, excessive pregnancy weight gain and risk of maternal obesity. Maternal Child Health Journal,18,554-562.

De Silva, S.(2013) Obstetric sequelae of female circumcision. European Journal of Obstetrics Gynecology and Reproductive Biology, 32,(2)233-240.

Etuk, S.J., Etuk, I.S., Ekott, M.I.\& Udoma, E.J. (2000). Perinatal outcome in pregnancies booked for prenatal clinic but delivered outside health care facilities in Calabar, Nigera. Acta Tropica, 75, 29-33.

Hakim, L.Y. (2012). Impact of female genital mutilation on maternal and neonatal outcomes during parturition. East African Medical Journal,78(5), 255-58.

Hill, K., Thomas, K., AbouZahr, C., Walker, N., Say, L. \& Inoue, M.(2007) Estimates of maternal mortality worldwide between 1990 and 2005: An assessment of available data. The Lancet, 370,1311-1319

Shah, I.H. \& Say L,. (2007) Maternal mortality and maternity care from 1990-2005: Uneven but Important Gains Reproductive Health Matters, Maternal Mortality and Morbidity: Is Pregnancy Getting Safer for Women? Reproductive Health Matters, 15,(30)17-27.

Shandall, A.(2007). Circumcision and infibulations of females: a general consideration of the problem and a clinical study of the problem in Sudanese women. Sudan Medical Journal, 5: 178-206.

Ujah, I.A.O. \& Ejej, I.S. (2011) Postpartum hemorrhage and maternal mortality in Nigeria. Sapiens Publishing Source: www.sapienspublishing.com/pph

UNFPA (2008) .The Role of traditional/religious leaders on reduction of maternal mortality and survival of women. UNFPA: Nigeria. Source: www.nigeria.unfpa.org.

WHO (2007). Maternal mortality in 2005; Estimates developed by WHO, UNICEF, UNFPA and The World Bank.Geneva.

WHO(2011). Maternal Health. Source: ww.who.int/topics/maternal_health/en/. Retrieved March, 2011. 